Article

\title{
Framing Corporate Social Responsibility to Achieve Sustainability in Urban Industrialization: Case of Bangladesh Ready-Made Garments (RMG)
}

\author{
Polin Kumar Saha ${ }^{1, *}$, Shahida Akhter ${ }^{2}$ and Azizul Hassan ${ }^{3}$ \\ 1 Environment and Sustainability Professional, Research Manager at Global Research and Marketing (GRM), \\ Mirpur 1, Dhaka 1216, Bangladesh \\ 2 Department of Development Studies, BRAC Institute of Governance and Development, BRAC University, \\ Dhaka 1212, Bangladesh; litun_tahsin@yahoo.com \\ 3 Tourism Consultants Network, The Tourism Society, 3 Port House, Square Rigger Row, \\ London SW11 3TY, UK; azizulhassan00@gmail.com \\ * Correspondence: polin.msls2009@gmail.com or polinksaha@gmail.com
}

Citation: Saha, P.K.; Akhter, S.;

Hassan, A. Framing Corporate Social Responsibility to Achieve

Sustainability in Urban

Industrialization: Case of Bangladesh Ready-Made Garments (RMG).

Sustainability 2021, 13, 6988. https://

doi.org/10.3390/su13136988

Academic Editor: Tan Yigitcanlar

Received: 11 May 2021

Accepted: 17 June 2021

Published: 22 June 2021

Publisher's Note: MDPI stays neutral with regard to jurisdictional claims in published maps and institutional affiliations.

Copyright: (C) 2021 by the authors Licensee MDPI, Basel, Switzerland. This article is an open access article distributed under the terms and conditions of the Creative Commons Attribution (CC BY) license (https:/ / creativecommons.org/licenses/by/ $4.0 /)$.

\begin{abstract}
According to both scholars and society, Corporate Social Responsibility (CSR) plays a controversial role in terms of corporate management towards sustainability. The business has presently become an integrated with the society and takes in a complex form of global demand for sustainability management. Due to the globalization of business, it is difficult to form a common sustainability model for CSR while its approach could be an opportunity for achieving sustainability. Evidently, a strong connection is found between the CSR approach and achieving urban sustainability since a smart urbanization requires a well-planned industrialization process that could be accelerated by the proper application of CSR. However, the CSR concept has already been initiated and developed in Western developed countries. Nowadays, it is being widely practiced by the developing countries as well. The developing country Bangladesh takes CSR issues seriously. Therefore, the study seeks the sustainability prospects of CSR by considering sustainability challenges in the rapid development of the "Ready-made Garments (RMG)" industry and corporate sector in Bangladesh. Finally, this paper explores some strategic paths to initiate sustainable development by framing the conditions and challenges of CSR.
\end{abstract}

Keywords: urbanization; sustainability; corporate social responsibility; ready-made garments; framework for strategic sustainable development; Bangladesh

\section{Introduction}

Corporate Social Responsibility (CSR) is an umbrella term which recognizes several issues such as companies' responsibility for their impact on society and the natural environment, sometimes excluding legal compliance and the accountability of individuals; companies' responsibility for the behavior of others with whom they do business (e.g., within supply chains); and the obligation to control its bonding with the wider community. Whether for motives of economic viability or to add value to the society, CSR calculates to various social initiatives ranging from community development and environmental protection to various socially responsible business practices [1,2]. Theoretically, CSR is still controversial, unclear and complex in its traditional approaches [3]. In practice, CSR theories try to address four dimensions related to revenue, such as social aspects, political demand and ethical values, wherever it takes into consideration in a company. However, environmental demand is significantly missing in those dimensions, since a new theory needs to develop an integrated model for achieving sustainability.

There is a dearth of CSR studies, and the significance of dealing with CSR as a strategy has already been executed, but in the developing countries such as Bangladesh, the concept is still an emerging one, especially in the ready-made garments (RMG) industry [4]. 
Here, the RMG platform is used for scrutinizing CSR because the current urbanization of Bangladesh has been developed mostly by the RMG industries. By conducting this research, the study objective is to find out the current CSR conditions in Bangladesh's RMG industry as well as its prospects towards sustainability management through existing CSR planning for the future of smart urbanization.

The implementation of CSR in a new environment faces decent challenges in several industries due to carelessness and because of disrespect for CSR by the producers and a continuous lack and abuse of workers' rights, the sustainability of the RMG industry is now in question. The industry is being threatened by its unsustainable infrastructure leading to fire, building collapse, mass death, labor unrest and violence [5]. Consequently, practicing CSR activities is very important for companies in developing countries such as Bangladesh, especially in the RMG industry [4]. It is not only the industry who is responsible to assure the social responsibilities, but there must also be contributions from the societies where they perform their activities. The study also focuses on the integration process of sustainability into CSR in general considering the existing CSR challenges in Bangladesh. Sustainability indicators, or the process of integrating sustainability into CSR, help organizations to simplify, analyze, quantify and communicate the whole planning system of this complicated issue [6].

The aim of this study is to find out the challenges of CSR and seek for sustainability prospects of CSR by considering those challenges in the Bangladeshi RMG industry. Specifically, the concrete research questions are: first, what are the existing CSR challenges in the Bangladeshi RMG industry and should they work towards corporate sustainability management? Second, and finally, in what ways could CSR be more strategic in line with sustainability management?

\subsection{Corporate Social Responsibility}

Ref. [7] states that organizations need to incorporate environmental and social indicators into organizational management practices in order to improve sustainability performances, even in the processes of voluntary legislation and guidance. The lack of a CSR approach may be alternatively defined as the Corporate Social Irresponsibility (CSI). However, both the promotion of CSR and reducing the impact of CSI may occur through the process of conceptualization and institutionalization [8]. This process involves a continuous negotiation process at the national and international levels. Therefore, the theories of sustainability opportunity influence the ultimate extended performance of CSR. In other words, corporate sustainability is also the ultimate destination of the organization where CSR is the intermediate stage of action towards sustainability, standing on three bottom line pillars of profit, people and the planet (3P) [9].

\subsection{Globalization and Corporate Social Responsibility Challenges}

"Globalization along with a parallel shift to outsourcing and offshore manufacturing has resulted to the concept of globally as a supply chain accordingly" [10]. Globalization happens mostly because of corporate societies' influence in the global economy. Due to technological, political, economic and cultural changes in society, the global business sector has become integrated. At the present period of urbanization versus globalization, international business is becoming more popular beyond the country boundary, where the implications of the business demand corporate sustainability based on the CSR activities [11]. In this case, the consumption patterns of an organization are a strong indicator for corporate sustainability that assess to what extent CSR contributes to what level of sustainability is achieved [12]. Meanwhile, global trade wars can be threatening issue on CSR and the global economy in the twenty-first century, as demonstrated by Figure 1 below. 


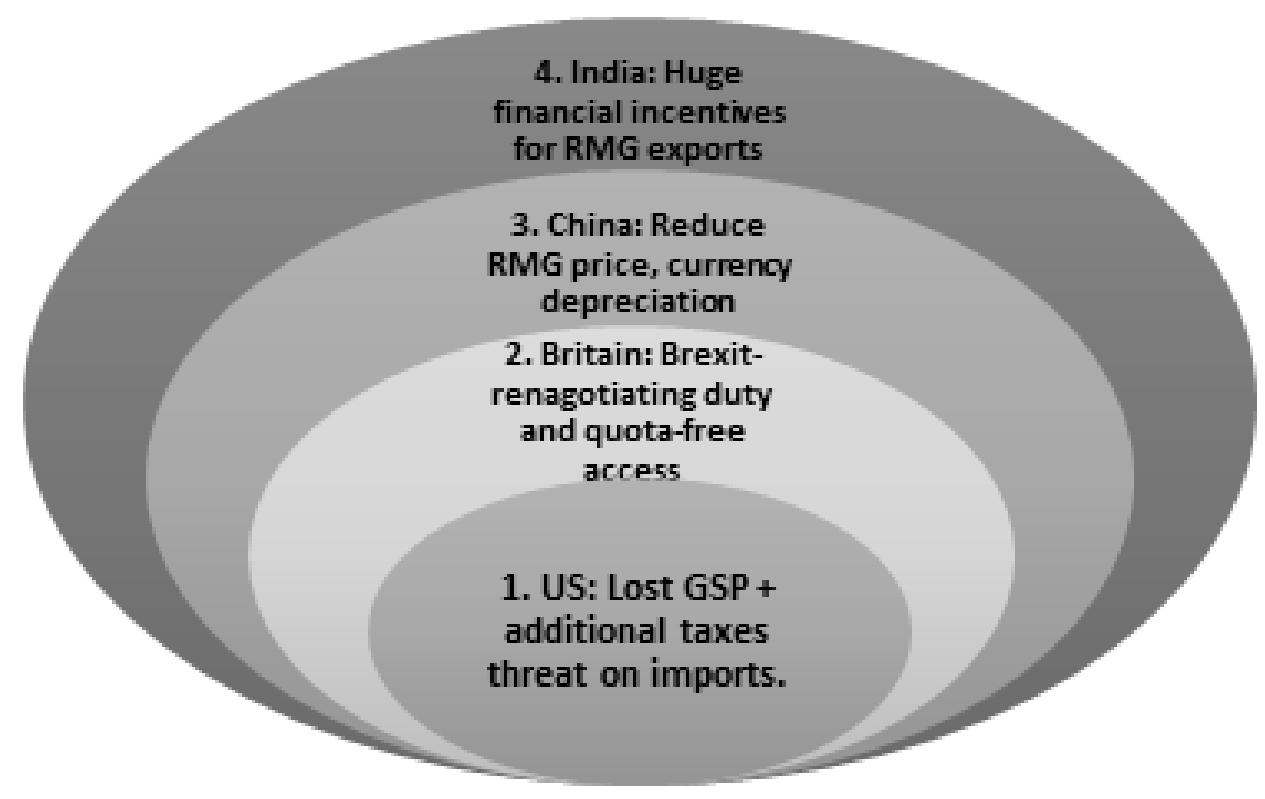

Figure 1. Global trade threat on CSR adapted from the Textile Today Bangladesh [13].

However, concerning the global phenomenon of corporate societies there is an ethical question raised by the author of [14]: will CSR reach full fruition as it becomes aligned, integrated and fully institutionalized within company strategies and operations? In the era of globalization, corporate societies have been operating in a market-based economy. Considering the major urban economy, various types of complexities imposed by different countries, for instance, India and Bangladesh, are the major impediments to the growth of bilateral trade and textile clothing value chain engagement between two countries such as India. However, both countries put a number of non-tariffs on textile and clothing products despite the agreement of cooperation between them due to their domestic CSR alongside social growth. Operations in market-based economies beyond borders needs proper regulation besides ethnicity. CSR in a market society has been discussed for decades, long before globalization became a buzz word [15]. While corporate societies are taking initiatives in their own interest, external regulation, e.g., government, institutional, is not a key issue to focus. In addition, there are some other factors which can challenge all the CSR initiatives taken by corporate societies. Day by day, corporate societies from different parts of the world are becoming integrated with each other. This integration brings a new challenge to the CSR initiatives.

Therefore, many social challenges arise, which are primarily transnational issues. These types of transnational social challenges cannot be regulated by the existing rules. For example, the greenhouse gas problem has been originated by developed countries, but the poorer countries such as Bangladesh are paying the price. In this case, even is Bangladeshi corporate houses reduce CFC (greenhouse gas) production significantly, would it be able to improve the situation in a significant manner towards urban sustainability? There is no one to give the answer.

To sum up, the global phenomenon of CSR is a great concern that there should have global regulation in addition to the corporate initiatives. In a global context, a corporate house runs through different cultural, political and geographical conditions. Therefore, beyond-border corporate activities demand regulation in addition to the responsible activities. On the other hand, the globalized form of the economy makes corporate culture complex and companies always think about their own sustainability rather than their social obligations and responsibilities. 


\subsection{Corporate Social Responsibility Practices in Bangladesh}

In 1985, the UN adopted some basic CSR practice that were underway by the 1990s owing to the concern of international buyers from all nations that everyone should be considered as consumers regardless their incomes and social standing. At least stimulated by the potential of success, companies are increasingly adopting CSR practices, such as corporate philanthropy, Cause-Related Marketing (CRM), employee volunteerism, marginal support programs and other initiatives [16].

A forum of more than two hundred and fifty consumer organizations from all over the world stated that there should be four fundamental rights as a consumer, e.g., the human well-being and the right of proper environment. Ensuring the well-being of stakeholders and society as a whole, while maximizing the creation of shared value for the business owners, is what CSR aims to achieve [17]. However, researchers have stated that CSR offers various positive outcomes anticipated by the sellers and buyers such as customer trustworthiness, optimistic company image, cost decrease and achieving competitive advantage, all of which boost business performance [10]. According to the author of [18] has mentioned that CSR must be implemented: first, to eradicate extreme hunger and poverty; second, employment generating vocational skills; third, to ensure environmental sustainability; fourth, to promote of education, gender equality and empowering women; and, finally, to battle human immunodeficiency germ, developed immune deficiency disorder, malaria and other disease. These are the essential development pathways for us towards ensuring a smart city in the future.

\subsection{Investment Situation in the Ready-Made Garment Industry in Bangladesh}

In Bangladesh, the ready-made garments (RMG) sector has a greater potential than any other sector in terms of employment and foreign exchange earnings to reduce poverty and make a contribution to the national economy. This development of RMG has been initiated in most of the urban industrialization cases of the country. Along with its potential, the sector is also experiencing new challenges which can be the future determinants of its sustainability [19]. The journey of the RMG industry started in the late 1970s and since then has played a key role in the economy [20]. Within a very short period of time, it has become the largest export earner of the country through a major positive forward thrust in the early 1990s and socioeconomic status has increased in spite of lacking environmental practices. The RMG of Bangladesh globally exported over USD 24.49 billion in 2014-2015, compared to an amount of USD 12 million in 1984-85. The hold of RMG in the total export earnings reached more than $81 \%$ in the fiscal year of 2013-2014 and it shares almost $16 \%$ of the total GDP. The trend of the RMG industry's contribution is strongly predicted to be increased in the upcoming year [19]. This growth brings RMG industry under the microscope to find out its CSR activities and implications.

\subsection{Framework for Strategic Sustainable Development}

The Framework for Strategic Sustainable Development (FSSD) had been used as the theoretical approach to intervene the whole process of data analysis. The framework has five unique components that are interrelated in functioning and the whole function is the collective output of this five-level framework (Figure 2). 


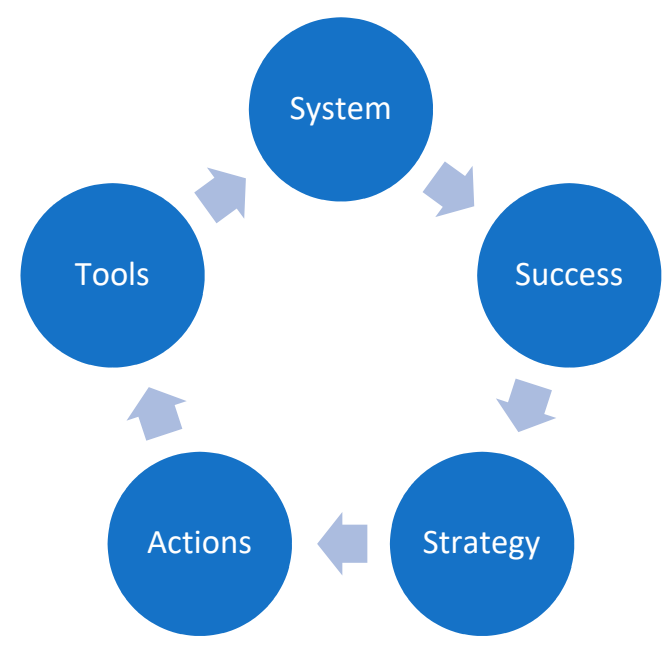

Figure 2. Five-level framework for strategic sustainable development [21].

A brief introduction of the five levels of the framework is as follows:

System: Principles to understand the services entire the organization and forming the whole organizational system towards more strategic as well as sustainable operations.

Success: Principles to define the success of the entire organizational system-basic principles "System Conditions" are a set of 'rule of thumb' practices to achieve success [22,23]. "System conditions" to achieve success are briefly illustrated as:

In a sustainable society, nature is not subject to systematically increasing ...

... concentrations of substances extracted from the Earth's crust,

... concentrations of substances produced by society,

... degradation by physical means

and, in that society ...

... people are not subject to conditions that systematically undermine their capacity to meet their needs.

Strategy: Strategy to reach at success which is defined through 'system conditions', which means sustainability principles.

Actions: Actions in corresponding to the assessment by tools and strategic guidelines executed by the principles of sustainability.

Tools: Tools that facilitate compliance with some principles and can be properly reported through the execution of sustainability principles (defined in 'success' level) in a system. Tools also can help to assess the performance of organizational policies to measure the success of any kind of tools that have been using in an organization to achieve success as well as facilitate capacity building of the people on human resource management, empowerment and knowledge management $[22,23]$.

\subsection{ABCD Analysis}

The strategic planning tool "ABCD" had been first developed by an international NGO, the Natural Step International. Beginning with the above framework, the tool was used here to assess the performance of Corporate Social Responsibility in RMG industries in order to make it a more strategic way for movement towards sustainability in urban development. This planning had four sections of analysis and the findings out of this analysis are then incorporated into organizational policy and planning for achieving sustainability within different modes of actions (short, mid and long term). The meaning of four sections of this planning process had been guided in the following ways (Figure 3): 


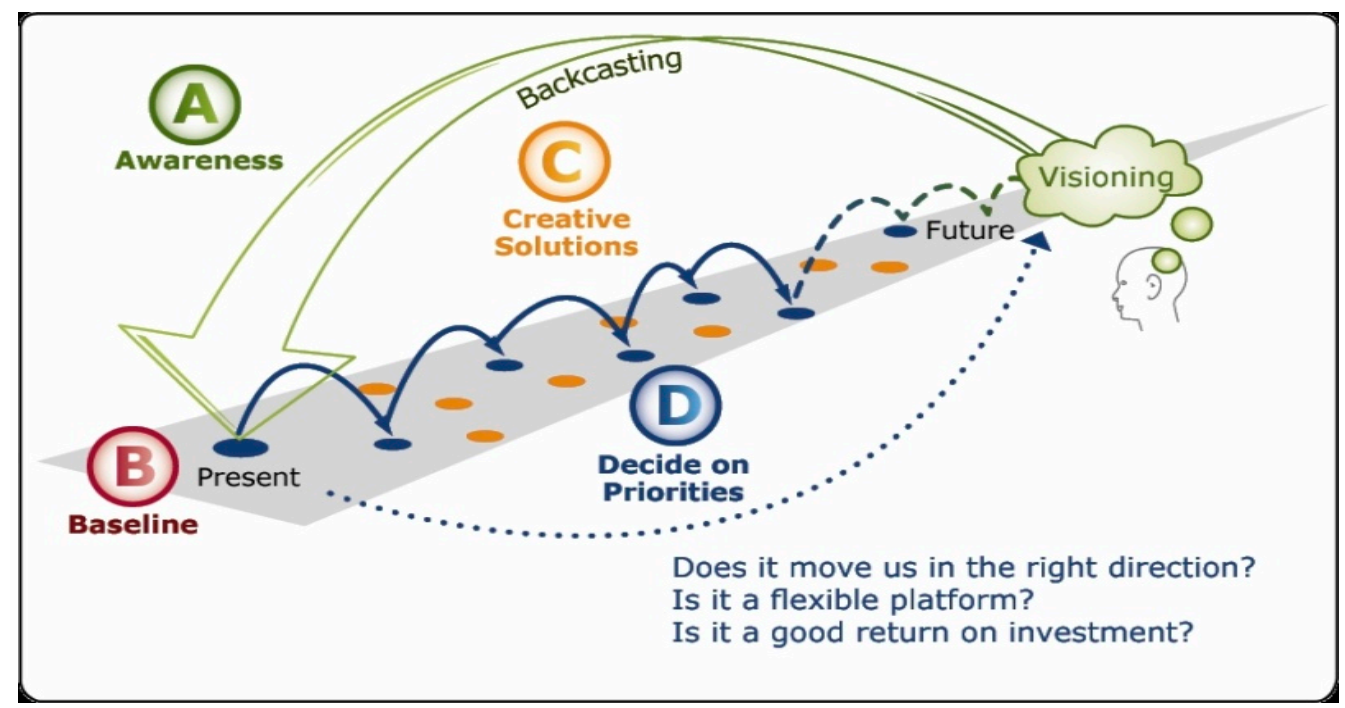

Figure 3. Diagram of the ABCD process [24].

"A" denotes Awareness and Visioning of an organization towards sustainability.

" $\mathrm{B}$ " indicates Baseline Mapping, which is conceptualized through the designated four sustainability principles to identify the 'sustainability gap' out of the major impacts of organizational activities.

"C" means the creative solutions that are developed in line with the findings out of " $B$ ", the baseline mapping.

" $\mathrm{D}$ " introduces the decision on priority basis depending on what type of problems are identified in the baseline findings.

\subsection{Conceptual Framework of the Study}

Based on overview of the corporate sustainability challenges, the following conceptual path can be shown for the study (Figure 4):

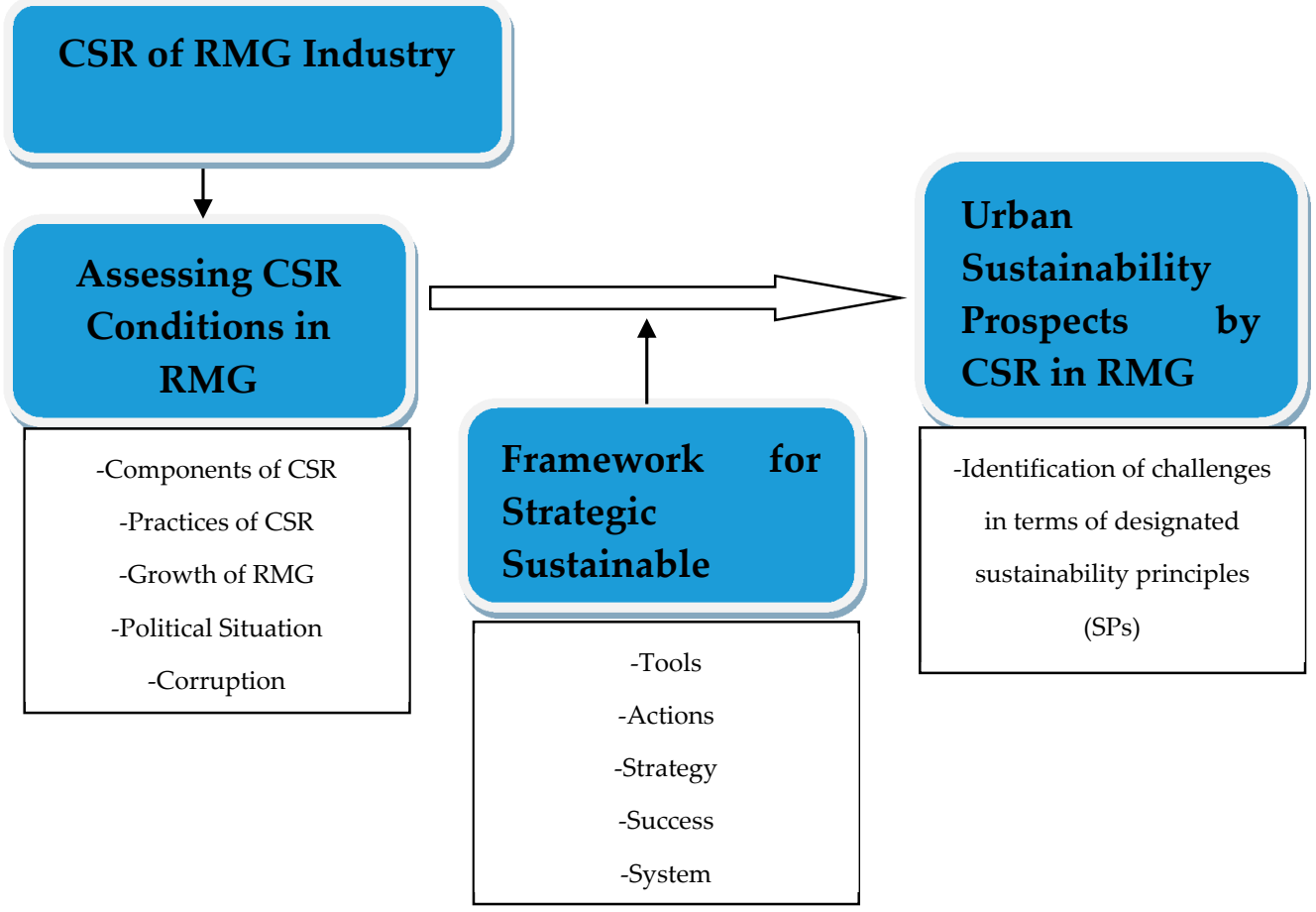

Figure 4. Conceptual framework of the study (Primary Source). 
From the above framework, it can be shown that the study would analyze the CSR conditions based on five significant indicators, e.g., existing CSR components, CSR practices, growth of RMG, political situation and corruption. This assessment supports the study for final output, which is a scope of integrating sustainability into CSR considering its implementing challenges in Bangladesh. Here, the Framework for Strategic Sustainable Development (FSSD) is the intervening variable used to assess the system of CSR and its definition of success based on the designated four sustainability principles. Furthermore, the framework builds up some strategic guidelines for corporate sustainability practices through the existing CSR planning. The designated ABCD tool can be defined at the tool section of the FSSD. Therefore, among the five levels of the FSSD, two levels (system and success) are applied in assessing the CSR condition. On the other hand, the remaining three levels (strategy, actions and tools) are applied as the intervention in framing the corporate CSR towards sustainability. Details of the FSSD are discussed in the following Methods section.

\section{Methods}

The study followed a qualitative approach to find out the possible answer and in-depth knowledge about CSR challenges in Bangladesh. The paper attempted to fill in the void of CSR literature by investigating the underlying reasons of its socially lacking in responsible business practices [5]. The study was developed on literature reviews and a case approach of RMG industries in Bangladesh. The case was designed in single embedded with a type of instrumental analysis of the selected corporate sectors in Bangladesh. This instrumental case was specially focused on the theoretical explanation of the particular issues linked with several departments of an organization. All of the data used for analysis and discussions collected from the secondary resources. The discussion was developed on existing CSR theories to reach our conclusion.

\subsection{Sample Size and Data Collection}

The RMG industry and corporate sector is considered as the study experimental unit. A sample of 15 stakeholder groups had been selected in the study. The selected stakeholders were the internal CSR management representatives of the ready-made garments sectors. All the stakeholders were selected from three categories of garments industries such as large, medium and small types of industries in the Dhaka City area. Five stakeholders were selected randomly from each type of industry. Among all the samples of data sources, nongovernmental groups of stakeholders had been selected. Identification of key stakeholders was a concern of the right approach to review CSR activities since they were on the way forward to sustainability through their existing CSR policies. A qualitative questionnaire tool is used to conduct interviews with the stakeholders. In the data collection, both on-site and off-site KII (Key Informant Interviews) were done to answer the research questions. For off-site data collection, telephone interviews were conducted or emailed responses were collected. Apart from the methods, the official websites and secondary materials of the stakeholder groups were used to gather information as well as the validation of the data. All the data had been analyzed thematically under the sustainability framework.

\subsection{Framework for Strategic Sustainable Development (FSSD) and ABCD Analysis}

Data analysis followed the FSSD and ABCD processes of analysis. By using the framework in any complex system, a good strategic analysis could be organized for moving towards organizational sustainability. To organize all kinds of information and thoughts about sustainability, the framework was applied in framing the whole system of the organizational function either in services or any kind of consumption matters. On the other hand, the ABCD planning method had been integrated in the analysis of the FSSD where the organizations were able to understand their clear vision for growth towards a sustainability-oriented approach [25]. 


\section{Results and Analysis \\ 3.1. $A B C D$ : ' $A$ '-Awareness \\ Components of CSR}

In the corporate sector, CSR had been described as a process and a set of obligatory activities of the firm to utilize its resources to contribute to the society. CSR was a process where corporations take actions to combine an integrated social and environmental effort in their business principles. Socially responsible business did not only indicate the fulfillment of the social legal expectations, but it was also something more to invest in a corporation's human capital [26].

Many corporations in the world have taken CSR actions as an aid or a compliancebased agenda. This was a very congested view of CSR. The following figure cited from the policy formulation study on reporting to The Millennium Development Challenge through Private Sector's Involvement in Bangladesh, 2009 and after that SDGs have also showed the components of CSR and the greedy component's predicate on community development into CSR. The social value's elements are shown below (Figures 5 and 6).

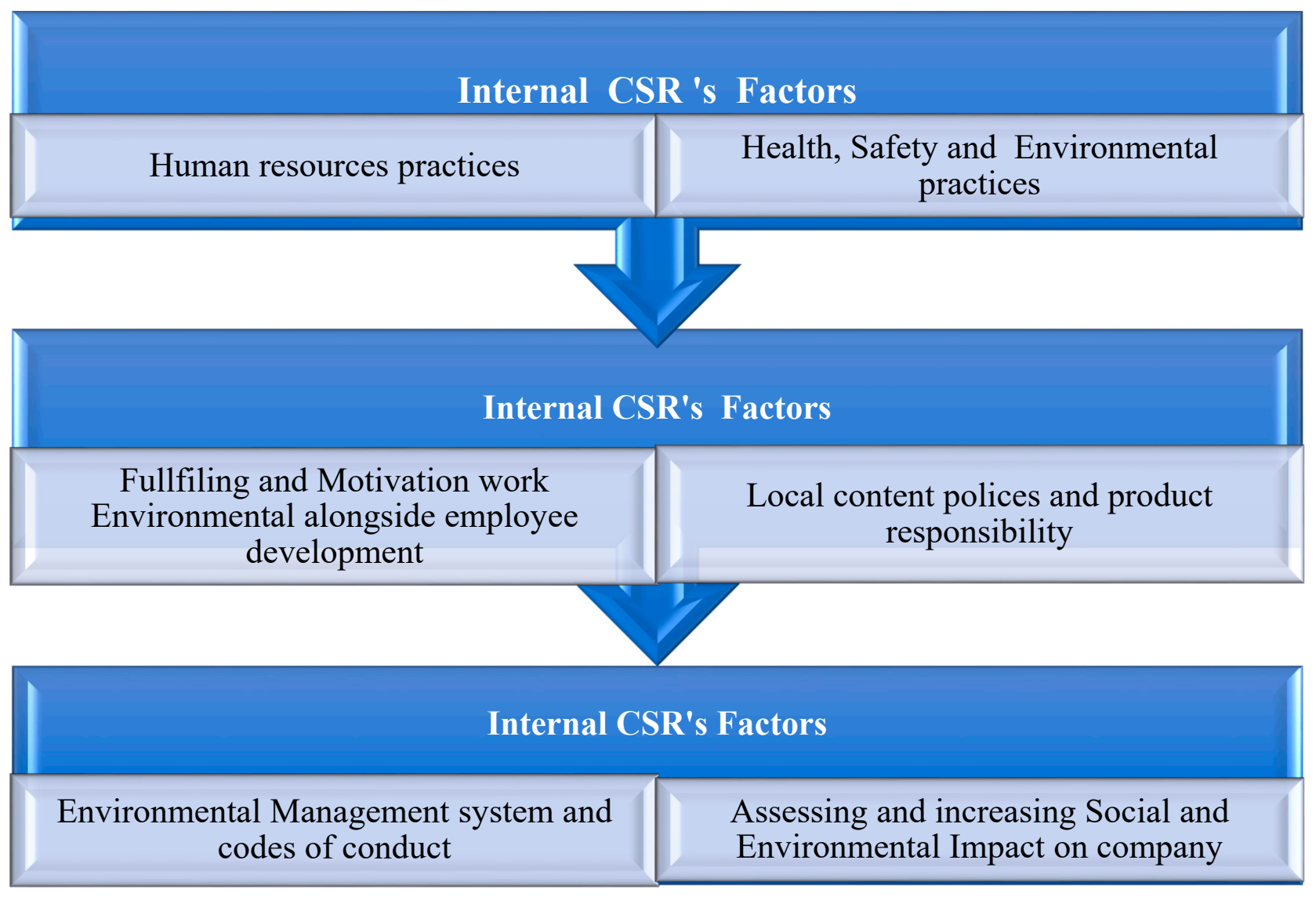

Figure 5. The social value's elements—internal (primary sources). 


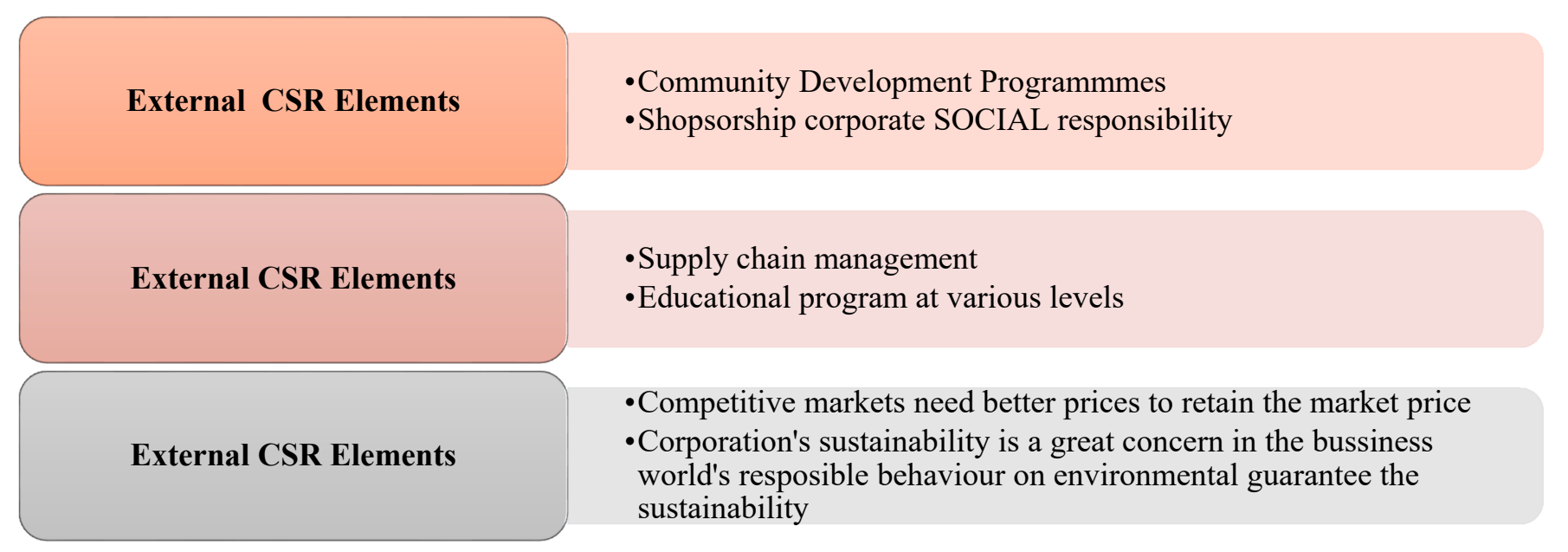

Figure 6. The social value's elements-external (primary sources).

\section{2. 'B' and ' $C$ '-Baseline Mapping and Compelling Measures of CSR}

CSR was highly in demand for market-oriented factors where no single way had been implied for its successful operation. Toward the long-term success of CSR operations, legal restriction was very flexible and manipulation was needed depending on capitalistic factors [27].

CSR came about mainly through companies' codes of conduct, which were operated by the directions of a company's commitments the obtained certificates and labor standards [28]. In this case, CSR was designated as "social upgrading" from the side of social, economic and some ethical issue including workers' payment, occupational health and safety, work environment and human rights [28]. Because of the overlapping nature in CSR, the code of conduct was very confusing in practice; therefore, its establishment was needed for a correct path of framework to analyze every sector of organizational operations associated with green social banking upgrading. Under the guidance of B and C, the performance of CSR components used in the corporate sector are as follows.

\subsubsection{Internal Positive Significance}

The RMG industry is a capital earning source of foreign currency where most employees of the major cities (e.g., Dhaka, Chittagong, Naryanganj, Gazipur) in Bangladesh are involved in the RMG sector directly or indirectly. It finds that the present urbanization was being inspired to be conducted with CSR compliance for safe working processes, environmental management and providing healthy work environments. The garments industry of Bangladesh helped the country's people in many ways to reduce the systematic barriers to top management positions and barriers to workers meeting their needs. It even relied on inputs of companies that also did not create obstacles for its employees to meet their needs. The customers and employees respected the traditions of work and they actually liked it because they thought it to ultimately represent Bangladesh. The RMG industry has a good financial position that would allow some necessary investment if they could guarantee a Return on Investment (ROI). The RMG industry of Bangladesh has achieved a positive global reputation through its sensitive services with low product-cost in the long term. In the service dimension of RMG, it is a very good platform to conduct with CSR compliance in the whole process of smart urbanization.

\subsubsection{Internal Negative Significance}

The RMG industry had no strong compliance to CSR. Different certification processes and their maintenance were still without the enforcement labor laws in practice. The major considerable issues had to look at CSR compliance as: first, all work place hazards were not taken proper care of; second, all genuine stakeholders' input usually were not incorporated 
into work traditions; third, all stakeholder concerns had not been documented; finally, overly long working hours did not exist in its entire success.

The treatment of customers and employees was not done in a proper professional manner that kept everybody satisfied, content and happy. The RMG industry did not reduce dependence on fossil fuels nor did it use them efficiently. Thus, energy efficient transportation was not being used in the industry. No obvious measures were taken to substitute persistent and unnatural compounds with ones that were normally abundant or that break down more easily in nature (oil, remnants, chemicals detergents, dyes and other pesticides, pp bags, nylon, aluminum foils). The industry was still using recyclable carton packaging, bleached paper and other packing materials. The waste was not well-managed depending on the municipality that took care of it after separation. The RMG industry did not draw resources from well-managed eco-farms.

\subsubsection{Political Barriers in Bangladesh}

As a crosscutting issue, the political movement of Bangladesh influenced the desirable outcome of CSR approaches in the corporate sectors. "Strike (Hartal)" was a Bangladeshi political phenomenon that deserves to be discussed in a broader level to find out its necessity as a political element. Hartal observed a wide spread of violations among two political parties' activists, polices and general people [29]. On the other hand, Bangladesh saw its biggest terrorist attack in July 2016 (claimed by Islamic State of Iraq and al-ShamISIS) at the Holey Artisan restaurant in Dhaka, where twenty people-mostly foreignerswere killed. Prior to July 2016, several incidents of foreigners and bloggers being targeted by ISIS and Al-Qaeda took place. It stopped all kind of factory production, export shipment and daily business in all sectors [30]. Increasing security challenges have hampered at least some investment and trade opportunities. It caused immeasurable losses to the country's economy and workers continue to protest working conditions and low wages. In other unpredictable consequences of these violations, the major issues included unsafe public movement, increased working hours, lower or delayed salaries, loss of competitiveness, factory insecurity, negative image of industries and raising the overall cost of production. Therefore, these are all factors that have affected the success of CSR implementation direct or indirectly.

\subsubsection{Corruption Barriers in Bangladesh}

Bangladesh is a new country on the world map, but the presence of corruption is not new. In 1757, the first step of corruption was seeded by the East India Company. Therefore, it was a business organization who paved the world of corruption in Bengal history. "Since the independence, Bangladesh's leader is often condemned with the high incidence of corruption, but even since the return of democracy 1990s, neither has able to take effective action to addressee the systematic issue which allow corruption to flourish" [31]. The business community had put up with it and benefited from it. One survey of World Bank stated that about $2-3 \%$ of GDP is lost due to corruption each year. The per capita income of the nation's people might be doubled if the government was able to prevent corruption [32]. The ethics and issues of conflicts of interest had not been accorded a priority for legislative and administrative reform. However, when the private business joined together to make deals with public officials for procurement contracts, concessions and privatizations were then a considerable issue in front of the corrupted administration [32]. Though the government had established an Anti-Corruption Commission (ACC), it failed to come out from the hand of political party's influence. However, the trend of such unethical practices in the corporate sectors dominated CSR planning and implementation, considering political or self-interest rather than overall attention to the community.

\subsubsection{Lack of Life Security System in Garments Industry and Threats to the International Market}

Although Bangladesh is recognized as one of the major apparel exporters in international market, the country has also been criticized for its poor CSR practices due to the 
low-quality life security in the industry. Corporations could be said to be socially accountable if they would not significantly damage their stakeholders, employees, customers, their investors, suppliers or local community. In the operation of the industry, they must be rectified whenever any damage is discovered [33]. Human rights and safety issues in the RMG workplace have also been defined by the industry's reputation compared to progress in the global market. In several cases, an abrupt accident stood up against on CSR, and international buyers have become strongly behind the cases. The path of success has become threats to life in the RMG industry (Figure 7).

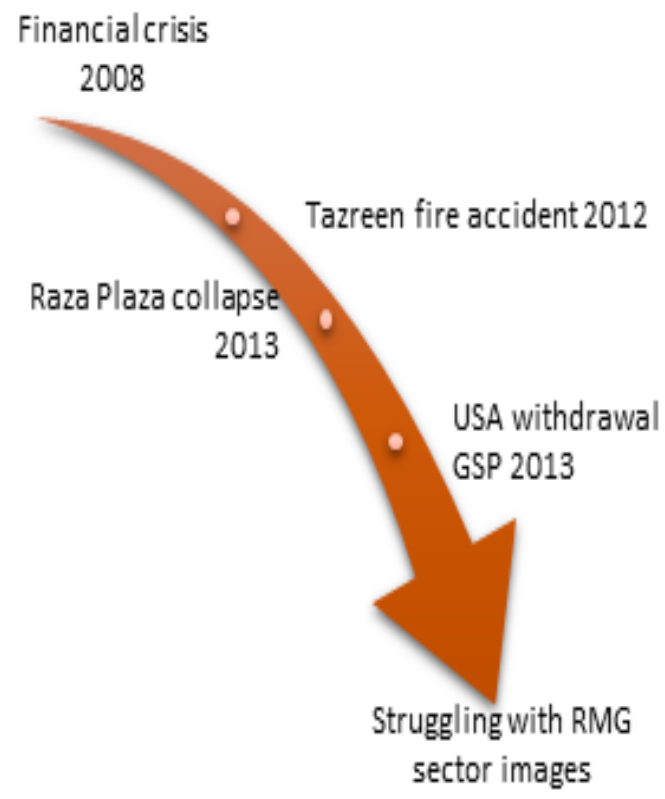

Figure 7. Indication of the path of the success with CSR in RMG industry adapted from Textile Today Bangladesh [13].

However, after the financial crisis of 2008, 112 garments workers had died and several hundred workers had been wounded by the Tazreen fire accident, and in the Rana plaza collapse, which was the biggest disaster, more than 1100 people were killed and over 2000 people were injured. The Trans-Pacific Partnership Agreement and the withdrawal of generalize system of preference by the USA were terrible for the RMG industry in Bangladesh. The crucial and unplanned damage to the image of the RMG sector may still be haunting the heart of readymade factory makers.

\subsubsection{Environmental Management and Disability in CSR}

A study [34] concluded that the conditions in which the RMG workers are set in causes health hazards such as fainting, eye strain, headache, jaundice, chest pain, asthma, fungal infections, helminthiasis, diarrhea, hepatitis, food poisoning, malnutrition, etc. The working conditions in several factories are subpar, and the absence of ventilation and light, lack of safe water for drinking and poor sanitation enables the development of diseases and viruses. Unfortunately, most of the factory owners are not aware of CSR in environmental sectors. Other difficult evidence about most of the garment factories stands at Ashulia and Tongi in Bangladesh. Unfortunately, there is normally no water management treatment plant in the dyeing industry. In Ashulia, liquid poison is mixed near the rivers and the water is black in the dry season. According to stakeholders and the local community, the factories are close to the river Bongshai and this river is a kind of dustbin for industrial waste. In this regard, all the factories inside or outside EPZ can be blamed in spite factory owners denying it. However, it is impossible to use the water of the Bongshai river. Moreover, the long-term ecological balance in the environment is reducing day by day as a result of weak environmental management. 
The Bangladeshi RMG industry needs to adopt cleaner and improved technology and management strategies for a better environment in order to achieve its CSR goals. Considering the buyers' demand and requirements, industry owners have set priority to implement the guidelines from the world-renowned organizations for eco-friendly production. However, the crucial challenges that are most important to gain sustainable environment in RMG's sectors are related to CSR. The implementation of CSR practices can be of immense help for developing the city's economy, society and the environment of a country such as Bangladesh.

The urban challenges are: first, a lack of waste management and low technology; second, occupational health and safety measures with training and capacity development; third, resource-inefficient production processes; fourth, "GREEN" factory building and fire safety; fifth, chemical management best practices; sixth, chemical hazard assessment, prioritization and action; sixth, efficiency of captive power generator has to be increasesd; seventh, carbon emission reduction and implementation of an Environmental Management System; eighth, identifying potential to manage and mitigate environmental pollution; ninth, waste management and recycling; and finally, control and reduce environmental flow.

Moreover, these challenges can be supported to build up an expensive CSR for sustainable management in the RMG world. On another important note, the sustainability aspect is the greatest issue in SDGs whereas the Bangladesh RMG industry needs a comprehensive strategy to be sustainable for environmental issues. CSR-based policy makers need to understand the global impact of production and consumption patterns. In order to achieve sustainable environment, stakeholders must design SDGs in the RMG industry in Bangladesh according to needs of practices such as: first, rain water harvesting; second, condensate recovery boiler; third, reduce, reuse, recycle (3R) water; fourth, water-efficient dyes and chemicals; fifth, the use of renewable energy (solar panel); sixth, Prismatic skylight and T5 and LED light; and finally, sustainability reporting.

To the point, those practice in several areas and according to CPD [35], "The UN 2017 report on its Sustainable Development Goals shows that the rate of progress in many areas, including sustainable energy and infrastructure, is far slower than needed to meet 2030 targets, and urges governments and all stakeholders to make more efforts. Sustainably run companies also have to fight entrenched short-term shareholder thinking, particularly activist investors keen to gain fast returns". Since CSR focused on the environment can become a very important tool for RMG, particularly in response to the current globalization process, the compliance issue with the achievement of SDGs could be accomplished through framing CSR design. However, there is still a lack of concern about human and environmental standards that could result in trade barriers negatively affecting the industry in Bangladesh. Bangladesh's RMG sector is a globally competitive business sector, but the lack of CSR in this industrialization can be threatening not only for the country but also the achievement of sustainability globally. The lethargic implementation of CSR in the RMG industry may introduce trade barriers as well as the country's GDP (Gross Domestic Product). More efforts to strengthen CSR in Bangladesh are needed to overcome international challenges and compliance that is now fundamental for this booming sector.

\section{3. 'D'-Priority Areas of Identified Problems and for Further Actions with CSR}

In the previous section of compelling measures, the following working areas of CSR had been considered. These areas were both the internal and external approach of the current CSR operations.

\subsubsection{Internal}

(1) Compliance with CSR was measured for the safety environment and accidents and injuries at the workplace. (2) HR Management that had been measured in an efficient labor force for increased productivity and profit for the business corporations. (3) Waste Management where environment friendly initiatives of corporations were conducted saved 
energy and earned more profit. These types of corporations got priority to access into the foreign market. The following components were important to consider into RMG industrial waste management. For garments: related solid and liquid waste through washing, dyeing and knitting; for food and beverages: through cooking and food service; for energy: fuel (personal and delivery cars); for packaging: product packaging and parcels; for hygiene: all about materials in practices relation to the occupational health and safety of workers; for lighting and other electronics: bulbs, projectors and fluorescent lights; and finally for stationary: papers, inks, printed materials and others office necessities.

\subsubsection{External}

(1) Supply chain management of CSR covered competitive markets which needed better pricing to retain the market share. A better supply chain could assure a better market position. (2) Social Investment of CSR considered corporate involvement with the community and its development activities gained media attentions and opened a window for earning more profit. (3) Environmental CSR indicated a corporation's sustainability that was a great concern in the business world's responsible behavior toward the environment and guaranteed the sustainability.

\section{Discussion}

\subsection{CSR in the RMG Industry in Bangladesh in Line with the Existing Challenges}

Most of the corporate businesses of Bangladesh are family-owned business as started from their first generation, and then converted by the RMG industry. On the other hand, these businesses are mostly operated from the major cities in Bangladesh, predominantly from Dhaka. However, in the 1960s and 1970s, when the marketing as well as social intellectuals were in progress of discussing CSR, they emphasized the social duties close to the marketing actions rather than on an overall social responsibility of the firm [36]. Different empirical studies also show that many small and medium enterprises fall under the informal sector without having the proper structures and resources to address social and environmental issues. This weakness drives the top management of local RMG companies to maximize their profits rather than considering the triple bottom line (people, planet and profit) issues [31,36].

The RMG industry of Bangladesh has been tremendously developed depending on the exports to developed countries. As a part of global market, it is difficult to ignore the CSR alongside environmental issues. It is evident from the RMG industry that the status of labor rights practices, environmental management, ex-post monitoring, risk management, low carbon technology and transparency in corporate governance are not yet satisfactory, largely due to the absence of poor enforcement of laws, weak participation of stakeholders to acquire their rights, lack of enforcement of backdated industrial laws and regulations, weak unions, lack of consumers' right groups and high levels of corruption. Within the regulatory authorities, these factors make CSR vulnerable in Bangladesh's RMG industry [31,37].

At present, there are still not sufficient uses of ethical business policies and CSR elements in the RMG sector. That is why not only child labor but also adult labor involved with RMG industry is facing discrimination. Though there has been a revision of the labor law in 2006, it is still based on the 1969 labor law. These forty-year-old labor laws are not sufficient to raise the CSR standard or to protect labor rights.

A good working environment is a key element to be assured by the socially responsible actions of corporations and organizations. A proper working environment and infrastructure is a fundamental right of workers. The RMG industry portrays a scenario where proper working environment is lagging far behind. The highest proportion of employment in the RMG industry is dominated by $80 \%$ women among 4.4 million workers. The provision for a woman-friendly work environment is rare in Bangladesh's RMG industry. An ILO paper [38] showed a concrete lack of CSR actions for women's work environment in the RMG industry such as inadequate childcare facilities on the factory premises; difficulties 
and irregularities getting maternity leave and benefits; scarcity of appropriate number of toilets; and congested work place in unsafe buildings.

The triple bottom line (people, profit and the planet) is one of the fundamental bases of CSR initiatives that are critically important for the urban sustainability of any country. Profit and maximum indicators in human approach are very important for any industry and that is why, an integrated path for sustainable CSR is necessary for ensuring a smart city. In the Resul section, issues about the integrated policies have been identified with the help of designated sustainability framework.

Employees are the life blood of any organization and industry. They are the most important element of stakeholder groups. Without strong stakeholder contribution, it is not possible to achieve the desirable standard of the CSR approach. By its name of CSR in garments industry, the outcome is expected from the relations between workers and their environment instead of making profit only. Therefore, a consideration of workers' demand into the CSR planning is a vital issue in order to improve the balance among social and economic return of the industry [39].

The RMG industry is a low-technology, labor-intensive industry that mostly depends on ready-to-export, turn-key factory units. Although the industry employs a great number of factory workers, lack of education and upgrading in jobs mean that workers have short shelf-life and are unceremoniously terminated after the end of productive years [40]. A labor union is a kind of institution that can facilitate the freedom platform to the worker. Unfortunately, there is no freedom of RMG associations in Bangladesh. Although union activities exist as a form of federations, their activities are prohibited at the factory level [41]

The study of CSR also suggests that without stakeholder participation, it is very difficult to integrate sustainability into social responsibilities. Stakeholder participation creates a platform where both parties can decide about their compliances. A consumer rights group can assure the mobility of stakeholder participation with corporation's CSR initiatives. On the other hand, labor unions in the industrial sector can play a significant role to protect their rights.

In more analytical findings, the CSR study suggests that without stakeholder participation, corporations can take advantage of CSR to retain their own interests, ignoring other parties' legal rights. To protect their own rights and ensuring more profit, RMG factories have been situated in Export Processing Zones (EPZs) in Bangladesh and have banned all kinds of union activities. Labors from EPZs agree with the government to create Workers Representative Welfare Committee. These types of committees are weak in nature and cannot make RMG factories implement CSR activities. On the other hand, getting the affiliation is very lengthy process.

CSR practice and profitability is embedded with the industrial principle. It is a natural phenomenon that industries firstly focus on profit, then their economic sustainability and their overall process of CSR activities to reach for their business goal. It is evident from the current financial market analysis, after the year 2005, that the Bangladeshi RMG industry [42] has been facing huge competition because of the elimination of the rigid quota system. The base of RMG product of Bangladesh is low-cost items. Low-cost items give lower profits compared to other types of products. On the other hand, lack of proper infrastructure, training and skilled labor productivity are becoming lower than other competitive countries. The scopes of training and skills development for Bangladeshi's RMG worker are very poor and a half a million skillful employees are foreigners. Investment in skilled labor development has not become a part of corporate culture and strategy in Bangladesh. Lower productivity leads to the cost of lower wages in order to gain better profit margins [38].

Bangladeshi political culture and corruption are a simultaneous challenge to each other. The involvement of corruption and political leaders in the corporate sector gives Bangladesh the position as one of most significantly corrupted countries in the world. According to the TIB (Transparency International Bangladesh) report [43], corruption is a form of indirect taxation. Because of the consequences of corruption, business establishment 
cost has become very high in Bangladesh. This widespread situation creates vulnerability for industries for achieving their sustainability. This corrupted culture also maintains a strong liaison between political leaders and labor unions. The RMG industry also has the same experiences. Indeed, the significance of corruption is not underestimated in Bangladesh, even it is considered as the regular way of life. Due to the presence of corruption in the country, all areas of business life are weakening the management ability of the business sector [44]. On the one difficult note that environmental management system is not strong and it has become a misgiving issue for employees and residential areas to increase in different diseases and threaten life, for instance, the Rana plaza collapsing due to corruption

To sum up, we would like to draw up recommendations to raise the CSR issues in a reasonable level. It is evident from the study findings that there is no baseline for the CSR standard all over the world. Corporations are a part of society, and as a part of society, they must obey the social duty, which is named by CSR. Regarding CSR implementation, the country must play a significant role. Modern society is talking about the state's roles in justifying the importance of CSR initiatives. In this regard, corporate governance also plays a significant role. In addition to corporate governance, the corporations should have to ensure the mass stakeholders' involvement with the corporate policy. The initiation CSR is a debatable concept itself. Corporations and the RMG industry in Bangladesh should ensure the implementation of CSR initiatives in more sensible way to send a clear statement that business is not beyond the society.

\subsection{Strategic Pathways towards a Sustainable RMG Industry in Bangladesh}

The RMG industry could make a tangible difference by contracting with eco-farms to provide customers with the best quality of eco-product. By planning this in company's CSR strategy, the RMG industry would champion the market through triggering this initiative, which might pave the road for others to join. Setting up new market values might also help the government make brave decisions in this regard. However, and since there were many operational strategies to establish and maintain CSR policy in the RMG industry, many industries could work together to make the shift easier, smoother and tangible. The strategic path of CSR could be a foundation under the basis of the ABCD analysis found in the "Results" section.

\subsubsection{Awareness (A)}

In this way, an organization will evaluate its present understanding on sustainability and identifies the common language to create a visionary platform for future sustainability actions. The approach of ' $\mathrm{A}$ ' can be influenced by all sorts of present actions for social, ecological and environmental development within the business context. The understanding of sustainability may be back casted from the designated sustainability principles [45] Here, four sustainability principles scrutinize the whole system of organizational actions to understand sustainability. Those are already mentioned in the previous section of the sustainability framework.

However, throughout the understanding of organizational sustainability, the visioning for sustainability is to be set up as an ambitious goal. People are to be encouraged about sustainability all over their understanding process of sustainability in existing work.

\subsubsection{Baseline and Compelling Measures (B and C)}

In other way, this analysis also runs the evaluation and monitoring of organizational services to see how the prospective positive changes can be introduced towards sustainability based on those sustainability principles. The analysis identifies the critical sustainability issues, values and implications through different monitoring tools within the organization.

It is the process of potential brainstorming which certainly creates innovative solutions to get rid of the existing unsustainable practices in organizations. To be more innovative organizations also go back to their sustainability vision produced from " $\mathrm{A}$ " part. This 
process can be termed as "Backcasting", which is very helpful in developing strategy to solve the identified problems (sustainability gaps of B section).

\subsubsection{Priority Areas of Action (D)}

The decisions are to be a good return on investment in regarding economic, social and environmental returns. This decision can take many actions flexibly, which are categorized in different mode of actions, e.g., short-term, mid-term and long-term measurements.

However, under the analysis of the ABCD model, the combined findings of CSR could be integrated into the Framework for Strategic Sustainable Development (FSSD). The CSR process ability to achieve sustainability can be analyzed using the four sustainability principles of FSSD, developed by The Natural Step. These principles are used as a protocol of the FSSD and subsequently develop the cyclic functions of the framework. The analytical discussion of the CSR in line with these principles is as follows.

The first sustainability principle works to reduce human contribution to the systematic increases in concentrations of substances from the Earth's crust. With this guidance, organizations take initiative to alternate some materials from their usage which are scarce in nature and also which can be replaced by any other abundant materials leading away from the dependency on fossil fuels. CSR can address fossil fuel use by advocating the use of solar energy, which includes wind, geothermal, biomass and photovoltaic energy. This option is verified through many certifications process including Green-e certified renewable energy certificates. The CSR process facilitates mining through the requirement of close loop cycling of some metals to reduce the amount of metals extracted. In reality, CSR process fails to address metal scarcity and does not think about its poor metal management practices that have the adverse impact to the community.

The second sustainability principle is to eliminate human contribution to the systematic increases in concentrations of substances produced by society. Today's practices of RMG certainly produce compounds whether solid, liquid or gaseous that breaks down the natural system. The CSR's ideology is based on the idea that an organization needs to become part of biological and technical social responsibility systems. The CSR has the scope to promote reducing and eventually eliminating the waste from production and the product itself through the 'waste equals food' concept. The organization promotes closed loop cycling that reduces the amount of resources used to produce waste. A CSR strategy may promote ppm (parts per million) limitations that address some metals' usage, but it does not specifically address many essential substances such as GHGs emissions in the implementation process. It is indirectly accounted for through the energy saving and material selection portion.

The third sustainability principle guides to reduce human contribution to the continuous physical degradation of nature through many forms of modification, introductions and over-harvesting. CSR process focus on sustainable wood harvesting by using the guidelines from a set of Forest Stewardship Council (FSC). The uses and discharge of water are also a part of CSR conduction adopted by water stewardship guidelines. However, the present practices of CSR fail to address marine resources such as overfishing, trolling and other forms of overharvesting and also different agricultural impacts; those are specifically responsible for the physical degradation of the environment. Though the extraction of the mined materials, transportation and distribution system are indirectly involved to the physical degradation of the nature, but there are no rules or limitations in CSR regarding these to protect the physical quality of the nature.

The fourth sustainability principle says about our contribution as much as while society can move towards the meeting of human needs in our local community to global needs based on the process of substitution and dematerialization dealings taken within the first three principles. The CSR process of an organization may involve the efficient use of resources and this activity of the CSR is termed as "eco-effectiveness of the product". The CSR is also very conscious about the human needs and rights in the society that mostly satisfy the sustainability principles. In the tool system it has been maintaining the ten 
(10) principles of the UN global compact: A Pledge for Social Responsibility \& Corporate Ethics. However, CSR does not deal with some social issues in this principle such as no clear conception of social benefits (e.g., no boundaries of small scale vs. big scale projects and, as a result, small scale projects and/or poor countries feel lack of interest to use CSR), company reputation, border transitions of supply chain, etc.

\section{Conclusions}

CSR plays an important role in promotion for attaining business success, and CSR has many benefits for human rights, labors standards, environmental impacts, corruption reduction, workplace relations and gender discrimination in the workplace. That means social wellbeing included in the human approach should work in diverse ways for the sustainable environment of a city. In reality, CSR is not addressing many issues such as the challenges within the sustainable principles if it is considered for work towards sustainability. So, an unclear picture of the CSR objective can be termed as "Blind Spots" which explore the first research questions on CSR challenges and the scopes for work towards sustainability management at the corporate level.

Answering this research question, the paper has explored the current CSR challenges which exist in both Bangladesh RMG industry, or in general for the next design phase of urban sustainability. The current CSR issues in Bangladesh are still in the young age. It has to go in a long way to serve the society in a sustainable way within the optimum capacity of an organization. This paper has focused on current CSR conditions based on not only the existing social conditions, but also other sustainability factors that need to be addressed in the existing CSR. The study [5] claims that the "majority of RMG suppliers focus on profit maximization without complying required social compliance issues, but the real scenario is not the same. The suppliers are now conscious about CSR implementation as the most significant mechanism to survive in the market; if they do not go for CSR implementation, they will lose business order and have to leave the market".

On the basis of the first research questions, the findings suggest some ways to integrate sustainability in corporate CSR, which is the exploration of the second research question. In this regard, the study finds out some significant and concrete reasons behind the drawbacks of CSR issues globally. For framing the corporate sustainability achievements, a 'ABCD' analysis can be used in the traditional CSR practices. Moreover, the FSSD guides whole corporate process to measure the violated sustainability principles over the CSR approach. The FSSD principles help CSR strongly to be more strategic including all other scattered challenges for movement towards urban sustainability such as political situation, lacking knowledge in environmental management, a huge presence of corruption throughout the administrative matters, which include absence of strong consumer/stakeholder groups, inadequate ethical business principles, insufficient laws to protect corporate violations and absence of proper monitoring are mentionable. Therefore, the future research directions could be a direction towards sustainable CSR in other business platforms where these specific challenges are lensed through the disciplinary sustainability framework. In addition, the realization degree of corporate social responsibility is directly proportional to the degree of investment is not explained here due to the study limitations. The future investment vs. CSR in the RMG industry can be another full-phase research question for the future.

Author Contributions: Conceptualization, Methodology, Formal Analysis, P.K.S.; Investigation, Writing, Review and Editing, P.K.S. and S.A.; Validation and Project Administration, A.H. All authors have read and agreed to the published version of the manuscript.

Funding: The Research received no external funding.

Institutional Review Board Statement: The study excludes ethical review and approval due to the lack of humans and animals involved in the study.

Informed Consent Statement: Informed consent was obtained from all subjects involved in the study. 
Data Availability Statement: Collected primary data and review of secondary literature.

Conflicts of Interest: The authors declare no conflict of interests.

\section{References}

1. Du, S.; Bhattacharya, C.B.; Sen, S. Maximizing business returns to corporate social responsibility (CSR): The role of CSR communication. Int. J. Manag. Rev. 2010, 12, 8-19. [CrossRef]

2. Blowfield, M.; Frynas, J.G. Editorial Setting new agendas: Critical perspectives on Corporate Social Responsibility in the developing world. Int. Aff. 2005, 81, 499-513. [CrossRef]

3. Garriga, E.; Melé, D. Corporate social responsibility theories: Mapping the territory. J. Bus. Ethics 2004, 53, 51-71. [CrossRef]

4. Zabin, I. An investigation of practicing carroll's pyramid of corporate social responsibility in developing countries: An example of Bangladesh ready-made garments. IOSR J. Bus. Manag. 2013, 12, 75-81. [CrossRef]

5. Azmat, F. Understanding Responsible Entrepreneurship of Micro-Business in Bangladesh. 2008. Available online: http:// citeseerx.ist.psu.edu/viewdoc/download?doi=10.1.1.532.4881\&rep=rep1\&type=pdf (accessed on 20 May 2020).

6. Singh, R.K.; Murty, H.R.; Gupta, S.K.; Dikshit, A.K. An overview of sustainability assessment methodologies. Ecol. Indic. 2009, 9 , 189-212. [CrossRef]

7. Adams, C.A.; Frost, G.R. Integrating sustainability reporting into management Practices. Account. Forum 2008, 32, $288-302$. [CrossRef]

8. Windsor, D. Corporate social responsibility and irresponsibility: A positive theory Approach. J. Bus. Res. 2013, 66, 1937-1944. [CrossRef]

9. Mulkhan, U. Corporate Sustainability Reporting: A Content Analysis of CSR Reporting in Indonesia. J. Perspekt. Bisnis 2013, 1, 73-89.

10. Salma, U. Can Corporate Social Responsibility Be Used as a Marketing Tool by the Readymade Garment Suppliers in Bangladesh? 2016. Available online: http://hig.diva-portal.org/smash/get/diva2:942579/FULLTEXT01 (accessed on 20 August 2020).

11. Kolk, A.; Van Tulder, R. International business, corporate social responsibility and sustainable development. Int. Bus. Rev. 2010, 19, 119-125. [CrossRef]

12. Málovics, G.; Csigéné, N.N.; Kraus, S. The role of corporate social responsibility in strong sustainability. J. Socio Eco. 2008, 37, 907-918. [CrossRef]

13. Textile Today. Recent Challenges in Bangladesh RMG Industry and Possible way Outs. 2017. Available online: https://www. textiletoday.com.bd/recent-challenges-in-bangladesh-rmg-and-possible-way-outs/ (accessed on 10 June 2020).

14. White, A.L. New wine, new bottles: The rise of non-financial reporting. Bus. Soc. Res. 2005, 6, 1-6.

15. Ford, R.C.; Richardson, W.D. Ethical decision making: A review of the empirical Literature. J. Bus. Ethics 1994, 13, 205-221. [CrossRef]

16. Christofi, M.; Leonidou, E.; Vrontis, D.; Kitchen, P.; Papasolomou, I. Innovation and cause-related marketing success: A conceptual framework and propositions. J. Serv. Mark. 2015, 29, 354-366. [CrossRef]

17. Cisco. 2017 Corporate Social Responsibility Report. 2017. Available online: https://www.cisco.com/c/dam/assets/csr/pdf/ CSR-Report-2017.pdf (accessed on 12 June 2020).

18. Rani, P.; Khan, M.S. Corporate social responsibility (CSR): An analysis of Indian Banking sector. Int. J. Appl. Res. 2015, 1, 304-310.

19. Rakib, M.A.; Adnan, A. Challenges of ready-made garments sector in Bangladesh: Ways to overcome. BUFT J. 2015, 3, 77-90.

20. Haider, M.B. An overview of corporate social and environmental reporting (CSER) in developing countries. Issues Soc. Environ. Acc. 2010, 4, 3-17. [CrossRef]

21. Saha, P.K.; Seal, L. A strategic approach to Environmental Management Systems (EMS): An assessment of Sustainability in EMS to move toward Sustainability. Int. J. Environ. Sci. 2011, 2, 1093-1102.

22. Broman, G.I.; Robèrt, K.H. A framework for strategic sustainable development. J. Clean. Prod. 2017, 140, 17-31. [CrossRef]

23. Robèrt, K.H.; Broman, G.; Waldron, D.; Ny, H.; Byggeth, S.; Cook, D.; Johansson, L.; Oldmark, J.; Basile, G.; Haraldsson, H.V.; et al. Strategic Leadership towards Sustainability; Blekinge Institute of Technology: Karlskrona, Sweden, 2007; p. 221.

24. The Natural Step International. Planning for Sustainability: A Starter Guide; The Natural Step International: Stockholm, Sweden, 2012.

25. Saha, P.K. Strategic sustainability through a product development tool. In Green Design, Materials and Manufacturing Processes, Proceedings of the 2nd International Conference on Sustainable Intelligent Manufacturing, Lisbon, Portugal, 26-29 June 2013; SIM: Singapore, 2013; pp. 209-214.

26. European Commission. Promoting a European Framework for Corporate Social Responsibility; Office for Official Publications of the European Communities: Luxemburg, 2001.

27. Banerjee, S.B. Corporate Social Responsibility: The good, the bad and the ugly. Cri. Soc. 2008, 34, 51-79. [CrossRef]

28. De Neve, G. Power, Inequality and Corporate Social Responsibility: The Politics of Ethical Compliance in the South Indian Garment Industry. 2009. Available online: https://assets.publishing.service.gov.uk/media/57a08b6fe5274a31e0000b56/60620_ Power_inequality.pdf (accessed on 30 May 2020).

29. Odhikar. Bangladesh: Human Rights Defenders Trapped in a Polarised Political Environment. 2013. Available online: http: / / odhikar.org/ (accessed on 1 June 2020). 
30. Bangladesh-Market Challenges, 2018. Issue on Trade and Industry. Available online: https: / /www.export.gov / article?series=a0 pt0000000PAtGAAW\&type=Country_Commercial_kav (accessed on 10 August 2020).

31. Mahmood, S.A.I. Public procurement and corruption in Bangladesh. Confronting the challenges and opportunities. J. Pub. Adm. Pol. Res. 2010, 2, 103-111.

32. Ahmad, M. Governance, Structural Adjustment \& the State of Corruption in Bangladesh. In Background Paper for the National Forum of the Structural Adjustment Participatory Review Initiative; SAPRI Bangladesh: Dhaka, Bangladesh, 2001.

33. Campbell, J.L. Why would corporations behave in socially responsible ways? An institutional theory of corporate social responsibility. Acad. Manag. Rev. 2007, 32, 946-967. [CrossRef]

34. Nahar, N.; Ali, R.N.; Begum, F. Occupational Health Hazards in Garment Sector. Int. J. Bio. Res. 2010, 1, 1-6.

35. Centre for Policy Dialogue (CPD). Companies Are Shifting to Responsible and Sustainable Business Practices. 2017. Available online: http:/ /rmg-study.cpd.org.bd/companies-shifting-responsible-sustainable-business-practices/ (accessed on 30 May 2020).

36. Maignan, I.; Ferrell, O.C. Corporate social responsibility and marketing: An integrative framework. J. Acad. Marrk. Sci. 2004, 32, 3-19. [CrossRef]

37. Rahim, M.M. Legal Regulation of Corporate Social Responsibility: Evidence from Bangladesh. Common Law Word Rev. 2012, 41, 97-133. [CrossRef]

38. Khondker, B.H.; Razzaque, A.; Ahmed, N. Exports, Employment and Working Conditions: Emerging Issues in the Post-MFA RMG Industry; International Labor Office: Dhaka, Bangladesh, 2005.

39. Bode, N. Global Actors, Local Governance: Corporate Social Responsibility in the Indian Garment Industry. Bachelor's Thesis, Leiden University, Leiden, The Netherlands, 2013.

40. Dhaka Tribune. Can RMG Navigate All the Risks? 2020. Available online: https://www.dhakatribune.com/opinion/op-ed/20 20/05/12/can-rmg-navigate-all-the-risks (accessed on 30 May 2020).

41. The International Federation for Human Rights (FIDH). Bangladesh Labor Rights in the Supply Chain and Corporate Social Responsibility. 2008. Available online: http:/ /www.fidh.org/en/ (accessed on 30 May 2020).

42. Bangladesh Garment Manufacturers and Exporters Association (BGMEA). About Garments Industry. 2014. Available online: http:/ / www.bgmea.com.bd/home/about/AboutGarmentsIndustry (accessed on 20 May 2020).

43. Hassan, M.K. The Shadow Economy of Bangladesh: Size Estimation and Policy Implications; Transparency International Bangladesh Research Report: Dhaka, Bangladesh, 2011; pp. 1-21.

44. Zakiuddin, A.; Haque, W. Corruption in Bangladesh: An Analytical and Sociological Study; Transparency International Bangladesh: Dhaka, Bangladesh, 1998.

45. Holmberg, J.; Robèrt, K.H. Backcasting-A framework for strategic planning. Int. J. Sustain. Dev. World Ecol. 2000, 7, 291-308. [CrossRef] 